\title{
Dissolution Enhancement of Raloxifene Using Water Soluble Carrier by Solid Dispersion Technique
}

\author{
Nagasamy Venkatesh Dhandapani, Arun Radhakrishnan \\ Department of Pharmaceutics, JSS College of Pharmacy, Ootacamund - 643 001. Tamil Nadu, India
}

\begin{abstract}
Raloxifene is a second-generation selective estrogen receptor modulator used in the treatment of osteoporosis in women. The drug is practically insoluble in water and exhibits exceptionally slow and intrinsic dissolution rate with poor bioavailability. In the present study, raloxifene and $\beta$-cyclodextrin $(\beta-\mathrm{CD})$ solid dispersions were prepared with a view to study the effect and influence of $\beta-C D$ on the solubility and dissolution rate of this poorly aqueous soluble drug. Phase solubility profile revealed that the solubility of raloxifene was significantly increased in the presence of $\beta-\mathrm{CD}$ and was classified as $\mathrm{A}_{\mathrm{L}}$-type, indicating the possible 1:1 stoichiometric inclusion complex with a stability constant of $328.65 \mathrm{M}^{-1}$. Effect of variable such as drug: carrier ratio was studied. Physical characterization of the solid dispersion was characterized by Fourier transform infrared spectroscopy, differential scanning calorimetry, and X-ray diffraction studies. These studies revealed that a distinct loss of drug crystallinity in the solid dispersion is ostensibly accounting for enhancement of dissolution rate in distilled water containing $0.1 \%$ Tween 80 . The scanning electron microscopy study revealed that all the binary systems appeared as agglomerates and exhibiting the presence of a homogenous solid phase which could also be responsible for the enhanced dissolution rate in comparison with the pure drug. The drug release from the prepared solid dispersion exhibited the first-order kinetics. Solid dispersion of raloxifene showed a 6.77 times fold increase in dissolution rate over the pure drug.
\end{abstract}

Key words: $\beta$-cyclodextrin, dissolution, kneading method,raloxifene, release kinetics, solid dispersion

\section{INTRODUCTION}

$\mathrm{P}$ oor aqueous soluble drugs are generally associated with certain problems such as slow drug absorption which eventually leads to insufficient and variable bioavailability. ${ }^{[1,2]}$ Approximately $40 \%$ of the newly discovered drugs are reported to be poorly water-soluble ${ }^{[3,4]}$ In an economic point of view, low oral bioavailability results in wastage of large portion of drug and ultimately adds to the cost of drug therapy, especially when the drug is expensive one. ${ }^{[5]}$ Therefore, certain attempts have been made to enhance the drug solubility of these therapeutic agents to correlate well with enhancement of their bioavailability. ${ }^{[6,7]}$ Many techniques have been investigated by researchers to improve the solubility of poorly aqueous soluble drugs, among them solid dispersion technology was proven to be a successful technique, and most widely used. ${ }^{[8-11]}$ Numerous insoluble drugs have shown to improve their dissolution character on conversion to solid dispersion. ${ }^{[12]}$ Solid dispersion technology is a well-known process used to increase the dissolution kinetics and in turn alters the oral absorption of poorly water-soluble drugs using water-soluble inert carriers. ${ }^{[13]}$ The usage of hydrophilic polymers as carriers for the enhancement of dissolution of poorly water-soluble drugs has been gained greater interest. ${ }^{[14,15]}$ Hydrophilic carriers including polyethylene glycol, ${ }^{[16]}$ polyvinylpyrrolidone, ${ }^{[17]}$ and sugars ${ }^{[18]}$ are being investigated for the enhancement of bioavailability by the improvement of dissolution characteristics. Cyclodextrin

\section{Address for correspondence: \\ Nagasamy Venkatesh Dhandapani, Department of Pharmaceutics, JSS College of Pharmacy, Ootacamund, (A Constituent College of JSS Academy of Higher Education \& Research, Mysuru), Ootacamund - 643 001.Tamil Nadu, India. E-mail: nagasamyvenkatesh@rediffmail.com}

Received: 02-07-2017

Revised: 26-02-2018

Accepted: 10-03-2018 
(CD) is a cyclic $(\alpha-1,4)$-linked oligosaccharide of $\alpha$-Dglucopyranose, containing a relatively hydrophobic central and hydrophilic outer surface. Last two decades, $\mathrm{CD}$ and its derivatives have been attracted a considerable importance in the pharmaceutical field due to their flexibility in incorporation into formulations and exhibiting significant potential in forming complexes with a variety of drug molecules. CD is used to increase the solubility of water-insoluble drugs, through the formation of inclusion complexation. ${ }^{[19-22]}$ In general, the small drug molecules and those compounds with the lowest water solubility show a preferential increase in solubility as a function of $\mathrm{CD}$ concentration. Therefore, CD poses much more priority in their addition in pharmaceutical preparations to increase the stability and bioavailability of poorly watersoluble drugs. ${ }^{[23]}$ Natural CD has been used extensively for this purpose. However, they are characterized by relatively low solubility in water, which limits their application. Chemically modified versions of $\mathrm{CD}$ with their modified physicochemical properties are more considered in formulations. CD is known to form an inclusion complex with many drugs of appropriate molecular size and hydrophobic character. High solubility, bioavailability, and tolerability can be seen in the complex product of drug and cyclodextrin. Raloxifene is chemically [6-hydroxy-2-(4hydroxyphenyl)-benzothiophen-3-yl]-[4-[2-(1-piperidyl) ethoxy]phenyl]-methanone, a second-generation selective estrogen receptor modulator used to prevent osteoporosis in postmenopausal women, with higher lipophilicity ( $\log$ P 5.2). The major drawback of this drug is its poor aqueous solubility (BCS-II classification) $(0.25 \mathrm{mg} / \mathrm{L})$ and its oral bioavailability, that is, $2 \%{ }^{[24]}$ To overcome these difficulties, increase in the aqueous solubility of raloxifene is desirable. However, very few literature are available with this drug to improve the aqueous solubility. ${ }^{[25]}$ Hence, in this present investigation, an attempt was made for raloxifene by molecular inclusion complexation $\beta-C D$ with an aim to improve its pharmaceutical properties such as aqueous solubility, dissolution properties with a view of increasing its bioavailability, and therapeutic efficacy. The characterization of the drug, $\beta-\mathrm{CD}$, and complex was done using differential scanning calorimetry (DSC), Fourier transform infrared spectroscopy (FT-IR), and powder X-ray diffractometry (PXRD). In vitro aqueous solubility and dissolution rate profiles of the complex were performed.

\section{MATERIALS AND METHODS}

Raloxifene was obtained as a gift sample from RA Chem Pharm, Hyderabad, India. $\beta$-CD was obtained from Sigma, USA. All other materials used in the study were of analytical grade.

\section{Preparation of raloxifene $\beta-C D$ solid dispersion by kneading method}

A physical mixture of raloxifene and $\beta-C D(1: 1,1: 2,1: 3,1: 4$, $1: 5,1: 6,1: 7,1: 8$ and $1: 9 \mathrm{~mol} / \mathrm{mol}$ ) was wetted with a mixture of methanol and water $(1: 1 \mathrm{v} / \mathrm{v})$ thoroughly for $30 \mathrm{~min}$ in a glass mortar and pestle. ${ }^{[26]}$ The paste formed was dried under vacuum for $24 \mathrm{~h}$, dried powder was scrapped, crushed, pulverized, passed through sieve no 100 (ASTM-100, $150 \mu \mathrm{m}$ ), coded as RALSD-I to RALSD-IX and stored in desiccator for further studies. The prepared solid dispersions were evaluated for their physicochemical parameters such as yield, angle of repose, ${ }^{[27]}$ Carr's index, ${ }^{[28]}$ moisture uptake, drug content and in vitro dissolution studies.

\section{Solid state studies}

\section{Percent yield}

The percentage yield of the solid dispersion was calculated on the basis of dry weight and carrier with respect to the final weight of the inclusion complexes. ${ }^{[29]}$

$\%$ Yield $=\frac{\text { Final weight of the product }}{\text { Dry weight of the drug and carrier }} \times 100$

\section{Average particle size}

The solid dispersion of raloxifene was dispersed in liquid paraffin and mounted on slides. A random of 200 particles were measured using a calibrated stage micrometer and eyepiece micrometer, their average particle size was calculated. ${ }^{[30]}$

\section{Moisture uptake studies}

The solid dispersion was dried in a desiccator under anhydrous calcium chloride for 2 days. A known quantity (200 mg) of each formulation $\left(\mathrm{W}_{1}\right)$ was placed on a watch glass and exposed to ambient atmospheric conditions $(60 \pm 5 \% \mathrm{RH}$, $\left.25 \pm 2^{\circ} \mathrm{C}\right)$ and saturation humidity conditions $(75 \pm 1 \% \mathrm{RH}$, $25 \pm 2{ }^{\circ} \mathrm{C}$ ) for 2 days using a stability chamber (Thermo lab, Mumbai, India). The solid dispersion is reweighed $\left(\mathrm{W}_{2}\right)$ and percentage moisture gained was calculated using the formula,

Parentage moisture content $=\frac{\mathrm{W}_{2}-\mathrm{W}_{1}}{\mathrm{~W}_{1}} \times 100$

\section{FT-IR spectroscopy}

FT-IR spectra were recorded for pure drug, solid dispersions drug with different ratios of carrier $(\mathrm{w} / \mathrm{w})$ in $\mathrm{KBr}$ pellets using FT-IR - 5300 (Shimadzu, Tokyo, Japan). The scanning range was $450-4000 \mathrm{~cm}^{-1}$ and the resolution was $4 \mathrm{~cm}^{-1}$.

\section{DSC}

DSC analysis was performed for drug and drug in solid dispersions using DSC Q200, TA instruments, Mumbai, 
India. The samples ( $5 \mathrm{mg}$ of raloxifene or its equivalent) were heated in a sealed aluminum pan at a rate of $10^{\circ} \mathrm{C} \mathrm{per} / \mathrm{min}$ in a temperature range of $30-300^{\circ} \mathrm{C}$ under nitrogen flow of $40 \mathrm{~mL} / \mathrm{min}$. An empty aluminum pan was used as a reference.

\section{Scanning electron microscopy (SEM)}

The surface morphology of drug and binary systems was determined using a SEM. The raw materials and of the binary systems were examined by means of JSM-6390 (Tokyo, Japan). The samples were mounted onto the metal stabs using doublesided adhesive tape and then were made electrically conductive by coating with a vacuum with a thin layer of gold $\left(\sim 300^{\circ} \mathrm{A}\right)$ for $30 \mathrm{~s}$. The samples were subsequently analyzed under SEM for external morphology. The pictures were taken at an acceleration voltage of $20 \mathrm{KV}$ and a magnification of $\times 2000$.

\section{X-ray powder diffractometry (XRD)}

X-ray powder diffraction patterns were recorded in a Jeol JDX 8030 X-ray diffractometer (Tokyo, Japan) using Ni-filtered, $\mathrm{CuK} \alpha$ radiation, a voltage of $40 \mathrm{kV}$, and a $25-\mathrm{mA}$ current. The scanning rate employed was $1 \%$ min over the $10-30^{\circ}$

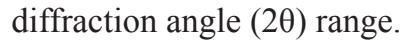

\section{Liquid state studies}

\section{Phase solubility study}

Solubility studies were performed according to the method reported by Higuchi and Connors. ${ }^{[31]}$ An excess of raloxifene $(50 \mathrm{mg})$ was added to screw-capped bottles containing various concentrations of $\beta$-CD solution $(0.2,0.4,0.6,0.8$, and $\left.1 \mathrm{mM} \times 10^{4}\right)$. All bottles were closed with stopper and covered with cellophane membrane to avoid solvent loss. Bottles were shaken mechanically at $25 \pm 0.5^{\circ} \mathrm{C}$ for $24 \mathrm{~h}$ using rotary flask shaker. After $24 \mathrm{~h}$ of shaking to achieve equilibrium, $5 \mathrm{ml}$ of aliquots were withdrawn, filtered $(0.45 \mu \mathrm{m}$ pore size $)$, and analyzed spectrophotometrically for drug content at $285 \mathrm{~nm}$ using ultraviolet (UV) 1700 spectrophotometer (Shimadzu, Japan).

\section{Estimation of drug content}

The content of raloxifene in the formulated solid dispersion was determined by UV spectrophotometer (Shimadzu, Japan). An accurately weighed quantity of solid dispersion (100 mg) was transferred into a beaker containing known volume of mixture of methanol and phosphate buffer (PH 6.8) (1:10). The solution was stirred for $1 \mathrm{~h}$ using a magnetic stirrer. The dispersion was filtered through Whatman filter paper $(0.45 \mu \mathrm{m}$ pore size $)$ and assayed for drug content at $285 \mathrm{~nm}$ spectrophotometrically.

\section{Dissolution rate studies}

Dissolution rate studies were performed using double distilled water $(900 \mathrm{ml})$ containing $0.1 \%$ of Tween 80 maintained at $37 \pm 0.5^{\circ} \mathrm{C}$, using USP XXII apparatus (Electro lab, Mumbai, India) with paddle rotates at $50 \mathrm{rpm}$. Solid dispersions from each formulation containing $50 \mathrm{mg}$ of drug were filled into capsule (size 2) and subjected to dissolution. At predetermined time intervals, $5 \mathrm{ml}$ of samples were withdrawn, filtered through Whatman filter paper $(0.45 \mu \mathrm{m}$ pore size) and spectrophotometrically assayed for drug content at $285 \mathrm{~nm}$. AUC of dissolution curve was calculated according to the Trapezoidal rule to determine the dissolution efficacy of the product and expressed as percentage of the area of the rectangle described by $100 \%$ dissolution in the same time ${ }^{[32]}$ (Equation 1). Data variations were analyzed statistically using one-way analysis of variance (ANOVA) procedure and significance was tested at $P$ values of 0.05 .

$D E=\frac{\int_{0}^{t} y \cdot d t}{y_{100} \cdot t} \times 100$

Dissolution percentage $\left(\mathrm{DP}_{10}, \mathrm{DP}_{30}\right)$, dissolution efficiency $\left(\mathrm{DE}_{10}, \mathrm{DE}_{30}\right)$, and time for $50 \%\left(\mathrm{t}_{50}\right)$ dissolution were calculated from dissolution data.

\section{Release kinetics}

The in vitro dissolution profiles of all molecular inclusion complexes of raloxifene were subjected to different kinetic analysis to elucidate the drug release mechanism. The release data were fitted into zero order (Equation 4), first order (Equation 5), Higuchi matrix model (Equation 6), and Hixon-Crowell (Equation 7) to understand the kinetic modeling of drug release.

$$
\begin{aligned}
& \mathrm{M}_{0}-\mathrm{M}_{\mathrm{t}}=\mathrm{K}_{0} \mathrm{t} \\
& \ln \left(\mathrm{M}_{0} / \mathrm{M}_{\mathrm{t}}\right)=\mathrm{K}_{1} \mathrm{t} \\
& \mathrm{M}_{\mathrm{t}}=\mathrm{K}_{\mathrm{H} v} \mathrm{t} \\
& \left(\mathrm{W}_{0}\right)^{1 / 3}-\left(\mathrm{W}_{\mathrm{t}}\right)^{1 / 3}=\mathrm{K}_{1 / 3} \mathrm{t}
\end{aligned}
$$

where $\mathrm{M}_{0}$ and $\mathrm{M}_{\mathrm{t}}$ correspond to the drug amount taken at time equal to zero, dissolved at particular time, t. The terms $\mathrm{M}_{0}$ and $M_{t}$ refer to the weight of the drug taken initially and at time $t$, respectively. Various other terms viz, $\mathrm{K}_{\mathrm{H}}, \mathrm{K}_{0}, \mathrm{~K}_{1}$, and $\mathrm{K}_{1 / 3}$ refer to the release kinetic constants obtained from the linear curves of Higuchi model, zero order, first order, and Hixon-Crowell cube root law, respectively.

Raloxifene was obtained as a gift sample from RAChem Pharm, Hyderabad, India. B-CD was obtained from Sigma, USA. All other materials used in the study were of analytical grade.

\section{RESULT AND DISCUSSION}

\section{Phase solubility study}

$\mathrm{CD}$ has been explored to be a powerful solubilizing agent for many poorly soluble drugs. To enhance the solubility 
of raloxifene, the phase solubility diagram of raloxifene with $\beta-C D$ in distilled water was constructed. The results revealed that $\beta-C D$ was found to be more effective in forming a solubilizing complex with raloxifene. The aqueous solubility of raloxifene was increased linearly $\left(r^{2}=0.9965\right)$ as a function of carrier concentration and corresponded to $A_{L}$ type. This finding was in accordance with other investigators regarding the solubility of halofantrine ${ }^{[33]}$ Since the slope of the diagram is $<1$, the complex stoichiometry was assumed to be $1: 1$. As the purpose of the study was not to prove the stoichiometry of the complex, based on this assumption binary system of raloxifene and $\beta-C D$ were prepared using 1:1 molar proportion. The extent of complexation is characterized by the apparent $1: 1$ stability constant $\mathrm{K}_{\mathrm{s}}$, which was calculated based on the solubility diagram according to the equation

$\mathrm{K}_{\mathrm{s}}=\frac{\text { Slope }}{\mathrm{S}_{0}(1-\text { Slope })}$

Where "S, denotes the solubility of raloxifene in the absence of $\beta-C D$. The value of the stability constant $\mathrm{K}_{\mathrm{S}}$ was $328.65 \mathrm{M}^{-1}$, which was adequately stable and well within the range of $100-1000 \mathrm{M}^{-1}$ and considered to be ideal. ${ }^{[34]} \mathrm{A}$ smaller the $\mathrm{K}_{\mathrm{S}}$ indicates too weak interaction, whereas a larger value indicates the possibility of limited release of drug from the complex by interfering with drug absorption.

\section{Physicochemical evaluation of raloxifene solid dispersions}

All the RALSD molecular inclusion complexes prepared with varying concentration of $\beta-C D$ were found to be fine and free flowing as indicated by the values of angle of repose $\left(22.17-24.45^{\circ}\right)$ and Carr's index $(10.17-11.42 \%)$ were within the official limits.

\section{Percent yield}

As shown in Table 1, the average percentage yield ranged from $94.15 \%$ to $98.74 \%$ for the molecular inclusion complexes. Low coefficient of variance values $<2 \%$ in percentage yield indicates the reproducibility of the technique employed for the formulation of molecular inclusion complexes. The oneway ANOVA test was performed among the percent yield of the different batches at $P<0.05$. Hence, the method used to prepare the solid dispersions was found to be reproducible.

\section{Average particle size}

The average particle size was found to be within the 50.35$106.22 \mu \mathrm{m}$. The narrow range of particle size was found to be satisfactory from the point of enhancing the aqueous solubility [Table 1].
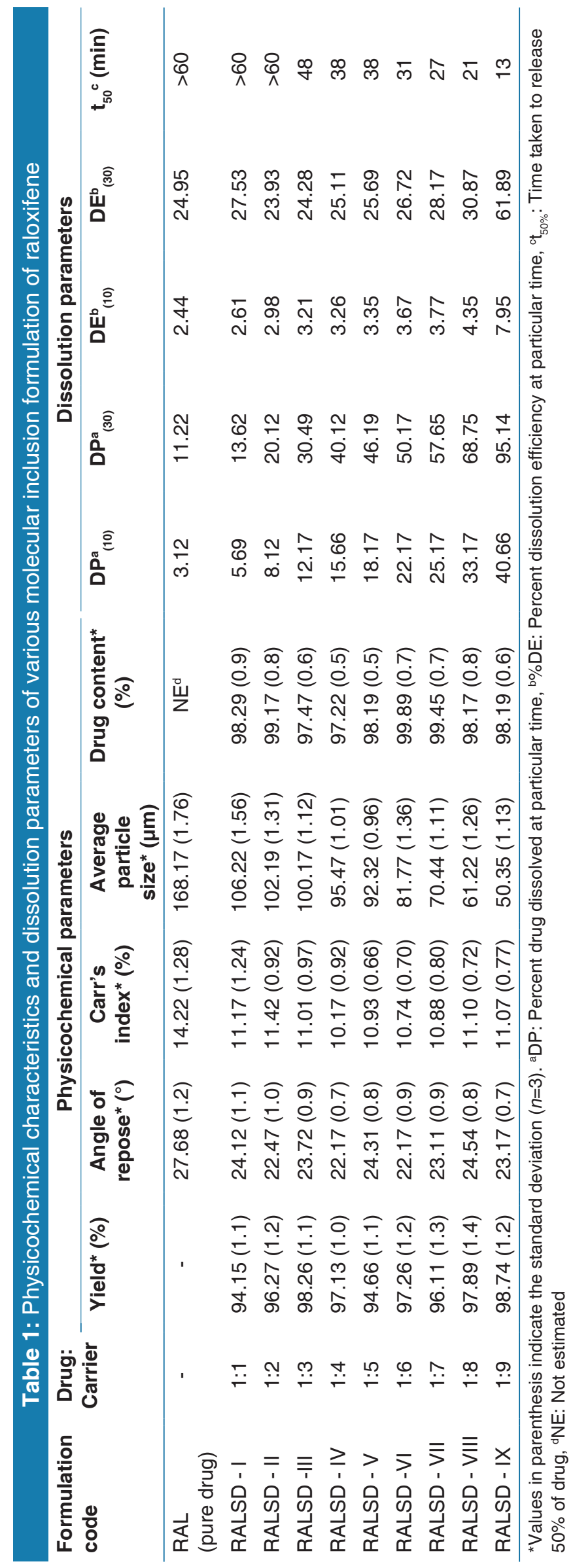


\section{Drug content}

The percentage of drug content in the molecular inclusion complexes were found to be nearer to the theoretical values with low values of standard deviation in respect of drug content indicated that the drug was uniformly distributed in all the solid dispersions [Table 1].

\section{Moisture uptake studies}

Result for the moisture uptake by inclusion complexes in terms of weight gain is shown in [Table 2]. The moisture uptake of inclusion complexes prepared using 1:9 molar ratio (RALSD - IX) was found to be more in comparison with the other formulations under ambient as well as saturation humidity

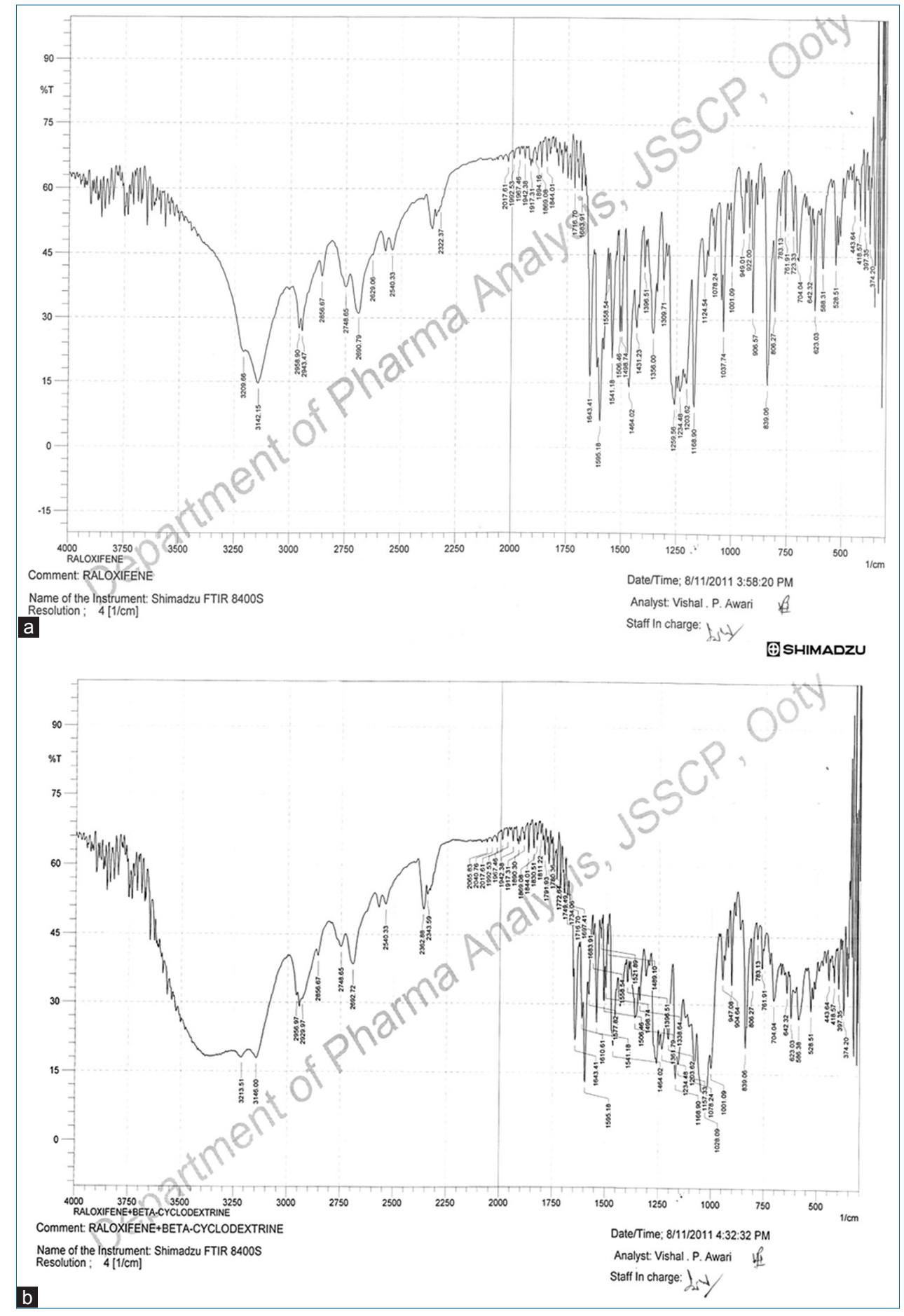

Figure 1: (a) Fourier transform infrared (FT-IR) spectra of raloxifene, (b) FT-IR spectra of raloxifene and $\beta$-cyclodextrin 
conditions. Our results comply with the similar reports by Sethia and Squilante ${ }^{[35]}$ and Martinez-Ohariz et al. ${ }^{[36]}$

\section{FT-IR}

Figure $1 \mathrm{a}$ and $\mathrm{b}$ shows the FT-IR spectrum of drug and its binary system with $\beta-C D$. The results depicted that there was no significant change in the spectrum of solid dispersion, as incorporation of raloxifene into the $\beta$-CD did not modify the position of its functional groups. All the major characteristic peaks of raloxifene observed at wave numbers, $2943 \mathrm{~cm}^{-1}$ $\left(\mathrm{CH}_{2}\right.$-stretching) and $1643 \mathrm{~cm}^{-1}(\mathrm{C}=\mathrm{O}$-stretching $), 1595 \mathrm{~cm}^{-1}$ $\left(\mathrm{C}=\mathrm{C}\right.$-aromatic), and $839 \mathrm{~cm}^{-1}$ (p-substituted benzene) were retained in the binary systems at the same wavenumbers indicating the lack of significant interaction between the drug and carrier in the solid dispersion. This may be an indicative of the drug monomeric dispersion, as a consequence of the interaction with $\beta-C D$ through hydrogen bonding, which could result in its inclusion into the hydrophobic cavity of the $\mathrm{CD}$. Shift of peaks from $3142 \mathrm{~cm}^{-1}$ to $3146 \mathrm{~cm}^{-1}$ (OH-stretching), $1037 \mathrm{~cm}^{-1}$ and $1259 \mathrm{~cm}^{-1}$ to $1028 \mathrm{~cm}^{-1}$ and $1234 \mathrm{~cm}^{-1}$ (C-O$\mathrm{C}$-stretching vibration) indicates a weak interaction between drug and $\beta-C D$. It was observed that when the carrier concentration was increased the characteristic peak of carrier was also increased while the intensity of drug peak decreased.

\section{Differential scanning calorimetric studies}

Thermogram of raloxifene and corresponding drug carrier systems was illustrated in [Figure $2 \mathrm{a}$ and b]. The DSC curve of raloxifene exhibits corresponding endothermic peak $\left(\mathrm{T}\right.$ peak $=267.5^{\circ} \mathrm{C}$ ) corresponding to its melting point. However, broadening and shifting toward lower temperature of characteristic peaks that corresponds to the drug melting point was observed with reduced solid dispersion intensity. This could be due to higher concentration and uniform distribution of the drug in the crust of carrier resulting in its complete miscibility. Moreover, this data also indicate that there seems to be no interaction between the components of binary systems. No significant difference in the DSC pattern of dispersions suggesting that the kneading process could not induce the interaction at molecular level and the solid dispersion formed as highly dispersed drug crystals in carrier.

\section{XRD}

XRD spectra of pure drug and binary systems with carriers were represented in [Figure $3 \mathrm{a}$ and $\mathrm{b}$ ]. The crystalline nature of raloxifene was clearly demonstrated by its characteristic PXRD pattern containing well-defined peaks. The diffraction pattern of pure raloxifene showed that the drug is crystalline as indicated by sharp peaks at diffraction angles $(2 \theta)$ at 21.49 , 23.32, 24.66, and 28.41 with intensities of 100, 77.8, 40.5, and 71 , respectively, showing a typical crystalline pattern. On the other hand, XRD of solid dispersion of raloxifene exhibited a significant decrease of crystallinity, as evident by the disappearance of sharp distinctive peaks. In addition, the intensity of raloxifene peaks at same diffraction angles were $46.8,25.6,32.3$, and 57.3, which reveals that the intensity of the peaks was remarkably reduced in solid dispersions indicating the amorphous state of the drug. The broadening diffraction peaks reveal that the inhibition of crystallization of raloxifene and converting it into amorphous form. However, the intensity of crystalline peaks of raloxifene in the solid dispersions was less than that of intact raloxifene, indicating lower crystallinity of raloxifene in the solid dispersions. Based on these data, we can confirm that a structural modification occurred in molecular state of raloxifene, the physical state of raloxifene is crystalline, but that of the carrier is amorphous. The formation of an amorphous state proved that the drug was dispersed in a molecule state in the carrier.

\begin{tabular}{|c|c|c|c|c|c|c|}
\hline \multirow[t]{2}{*}{$\begin{array}{l}\text { Formulation } \\
\text { code }\end{array}$} & \multirow[t]{2}{*}{$\begin{array}{l}\text { Drug: } \\
\text { Carrier (M) }\end{array}$} & \multirow[t]{2}{*}{$\begin{array}{c}\text { Initial } \\
\text { weight (mg) }\end{array}$} & \multicolumn{2}{|c|}{$\begin{array}{c}\text { Ambient conditions }(60 \pm 5 \% \\
\left.\mathrm{RH}, 25 \pm 2^{\circ} \mathrm{C}\right)\end{array}$} & \multicolumn{2}{|c|}{$\begin{array}{c}\text { Saturation humidity } \\
\text { conditions }\left(75 \pm 1 \% \mathrm{RH}, 25 \pm 2^{\circ} \mathrm{C}\right)\end{array}$} \\
\hline & & & $\begin{array}{c}\text { Final } \\
\text { weight }(\mathrm{mg})\end{array}$ & $\begin{array}{l}\text { Percent weight } \\
\text { gained }(\mathrm{mg})\end{array}$ & $\begin{array}{c}\text { Final } \\
\text { weight (mg) }\end{array}$ & $\begin{array}{l}\text { Percent weight } \\
\text { gained }(\mathrm{mg})\end{array}$ \\
\hline RAL (pure drug) & - & 200 & 200.4 & $0.4(0.1)$ & 200.5 & $0.5(0.2)$ \\
\hline RALSD - I & $1: 1$ & 200 & 200.6 & $0.6(0.09)$ & 202.5 & $2.5(0.22)$ \\
\hline RALSD - II & $1: 2$ & 200 & 200.6 & $0.6(0.06)$ & 203.2 & $3.2(0.27)$ \\
\hline RALSD -III & $1: 3$ & 200 & 200.5 & $0.5(0.08)$ & 203.4 & $3.4(0.33)$ \\
\hline RALSD - IV & $1: 4$ & 200 & 200.7 & $0.7(0.04)$ & 203.9 & $3.9(0.34)$ \\
\hline RALSD - V & $1: 5$ & 200 & 200.9 & $0.9(0.03)$ & 204.1 & $4.1(0.41)$ \\
\hline RALSD -VI & $1: 6$ & 200 & 201.1 & $1.1(0.12)$ & 204.5 & $4.5(0.32)$ \\
\hline RALSD - VII & $1: 7$ & 200 & 201.7 & $1.7(0.11)$ & 205.1 & $5.1(0.31)$ \\
\hline RALSD - VIII & $1: 8$ & 200 & 202.1 & $2.1(0.15)$ & 206.1 & $6.1(0.34)$ \\
\hline RALSD - IX & $1: 9$ & 200 & 202.9 & $2.9(0.17)$ & 206.9 & $6.9(0.41)$ \\
\hline
\end{tabular}

*Values in parenthesis indicatethe standard deviation $(n=3)$ 


\section{SEM}

Samples of raloxifene, kneading solid dispersion of raloxifene with $\beta-C D$ were examined by SEM. Raloxifene has appeared as irregular-shaped crystals and drug binary system constituted a relatively bulky particle, with a small one (raloxifene) adhered on its surface.The comparable morphology of these systems with pure drug revealed that apparently, no raloxifene-CD interaction had taken place in the solid state, although the number of raloxifene particles that adhered on $\beta$-CD surface was more in kneading method. The photomicrograph of dispersion shows topographical changes produced by carrier particles, resulting in more porous nature [Figure $4 \mathrm{a}$ and $\mathrm{b}$ ]. Solid state characterization studies revealed partial loss in drug crystallinity which could bring about significant change in drug dissolution rate. However, other factors such as reduced particle size, increased surface area, and closer intimacy of drug with hydrophilic carrier may also be attributed as influential parameters in enhancing drug solubility and dissolution rate.

\section{Dissolution rate studies}

Figure 5 illustrates the dissolution profiles plotted from the experimental values of pure raloxifene and its binary systems. These binary systems exhibit faster dissolution rates over pure drug. A complete dissolution of drug from sample from RALSD-IX $(99.86 \pm 1.1 \%)$ was achieved within $40 \mathrm{~min}$ from binary system, whereas pure drug showed dissolution of $20.12 \pm 0.8 \%$. Solid dispersions showed a 6.77 times fold increase in the dissolution rate over pure drug. The main dissolution promoting factor is probably the hydrophilic environment surrounding the drug due to the presence of $\beta-C D$, resulting in better wettability of the drug. The improvement in dissolution rate of raloxifene from the binary system was in accordance with the results of the solubility study [Figure 6]. As the amount of carriers increased in the formulations, $\mathrm{t}_{50}$ (time for $50 \%$ dissolution of drug) values were decreased. The $t_{50}$ values indicated that there was an enhancement in dissolution rates of RAL. The $t_{50}$ values of the batches prepared with 1:9 drug: carrier ratio was $13 \mathrm{~min}$. The batch prepared in the ratio of 1:9 (drug: carrier) showed better in vitro release and better $t_{50}$ values, when compared with the in vitro release of pure drug. The enhancement of dissolution of raloxifene from the carrier may be attributed to several factors such as lack of crystallinity, increased wettability, and dispersibility. Incorporation of a drug with hydrophilic carrier system offered an increased wetting and reduction in interfacial tension between hydrophobic drug and dissolution medium. ${ }^{[37]}$ The solid dispersion prepared using the molar ratio of 1:9 (RALSD-IX) exhibited maximum dissolution rate of the drug, i.e., $95 \%$ after $30 \mathrm{~min}$ and up to $99.86 \%$ after $40 \mathrm{~min}$; whereas pure drug exhibited $11.22 \%$ after $30 \mathrm{~min}$ and not more than $20.12 \%$ after $60 \mathrm{~min}$. Dissolution rates of RAL from solid dispersions followed first-order kinetics $(r>0.9984))^{[38]}$ Hixson-Crowell cube root law indicates That powder of uniform particle size

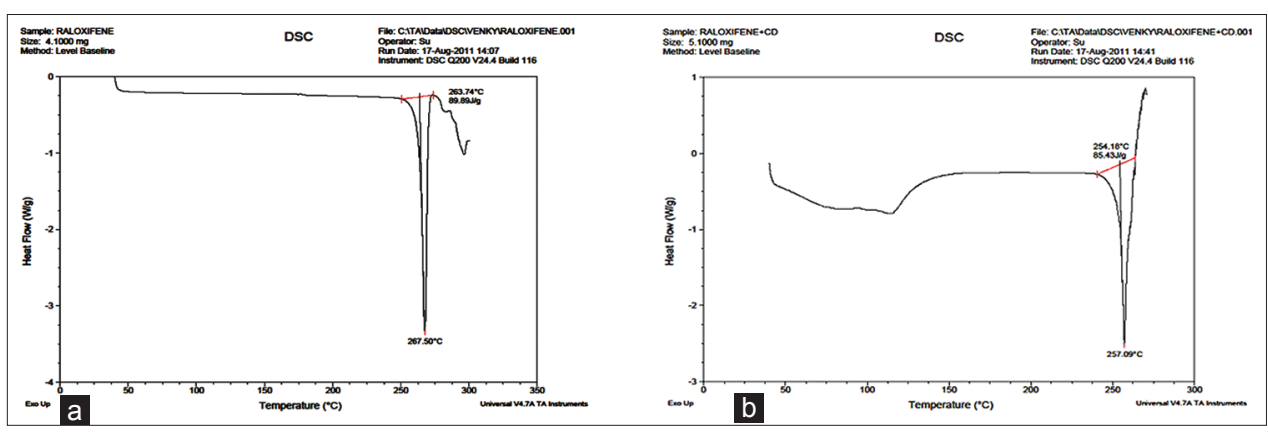

Figure 2: (a) differential scanning calorimetry (DSC) thermogram of raloxifene, (b) DSC thermogram of raloxifene and $\beta$-cyclodextrin

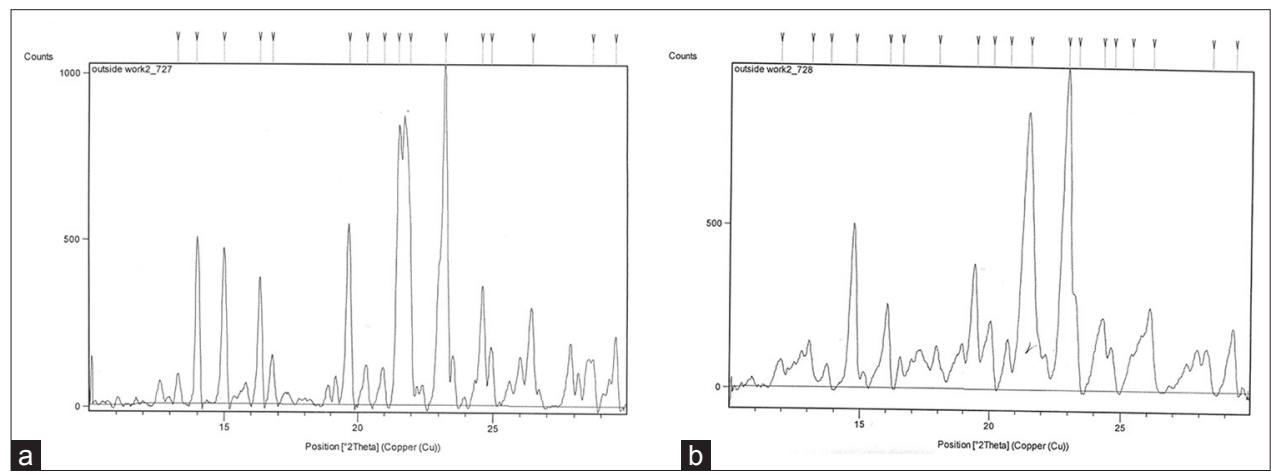

Figure 3: (a) X-ray diffraction (XRD) of raloxifene, (b) XRD of raloxifene and $\beta$-cyclodextrin molecular inclusion system 
Table 3: Comparison of different kinetic models applied on the in vitro release profile of molecular inclusion of raloxifene in distilled water containing $0.1 \%$ Tween 80

\begin{tabular}{|c|c|c|c|c|c|c|c|c|}
\hline \multirow{2}{*}{$\begin{array}{l}\text { Formulation } \\
\text { code }\end{array}$} & \multicolumn{2}{|c|}{ Zero order } & \multicolumn{2}{|c|}{ First order } & \multicolumn{2}{|c|}{ Higuchi } & \multicolumn{2}{|c|}{ Hixson-Crowell } \\
\hline & Slope (K) & $\left(r^{2}\right)$ & Slope (K) & $\left(r^{2}\right)$ & Slope (K) & $\left(r^{2}\right)$ & Slope (K) & $\left(r^{2}\right)$ \\
\hline RAL (pure drug) & 0.3457 & 0.9611 & -0.0016 & 0.9984 & 20.99 & 0.9614 & -0.0055 & 0.9844 \\
\hline RALSD - I & 0.4099 & 0.9960 & -0.0021 & 0.9974 & 24.98 & 0.9674 & -0.0070 & 0.9905 \\
\hline RALSD - II & 0.8222 & 0.9911 & -0.0049 & 0.9954 & 47.75 & 0.9186 & -0.0157 & 0.9800 \\
\hline RALSD -III & 1.065 & 0.9979 & -0.0072 & 0.9983 & 63.7 & 0.9483 & -0.022 & 0.9923 \\
\hline RALSD - IV & 1.2875 & 0.9969 & -0.0103 & 0.9977 & 77.90 & 0.9593 & -0.0295 & 0.9936 \\
\hline RALSD - V & 1.4712 & 0.9975 & -0.0145 & 0.9983 & 83.53 & 0.9642 & -0.0382 & 0.9907 \\
\hline RALSD -VI & 1.5157 & 0.9932 & -0.0164 & 0.9952 & 93.31 & 0.9713 & -0.0415 & 0.9920 \\
\hline RALSD - VII & 1.5757 & 0.9859 & -0.0195 & 0.9921 & 98.61 & 0.9800 & -0.0467 & 0.9905 \\
\hline RALSD - VIII & 1.6289 & 0.9725 & -0.0360 & 0.9936 & 104.71 & 0.9930 & -0.0628 & 0.9878 \\
\hline RALSD - IX & 2.542 & 0.9681 & -0.0679 & 0.9974 & 128.70 & 0.990 & -0.105 & 0.9913 \\
\hline
\end{tabular}

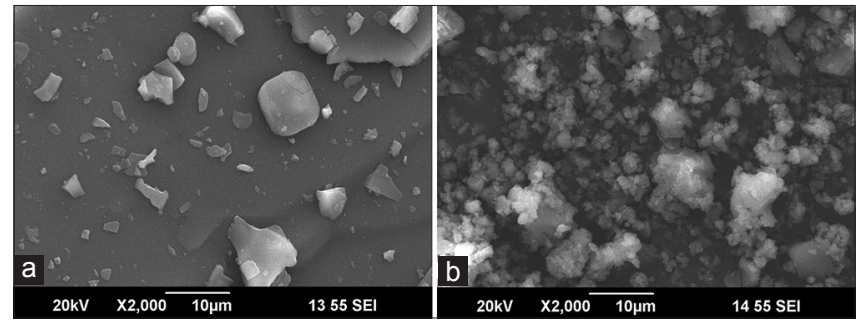

Figure 4: Scanning electron micrograph of raloxifene $(\times 2000$ magnification), (b) scanning electron micrograph of raloxifene and $\beta$-cyclodextrin molecular inclusion complexes $(\times 2000$ magnification)

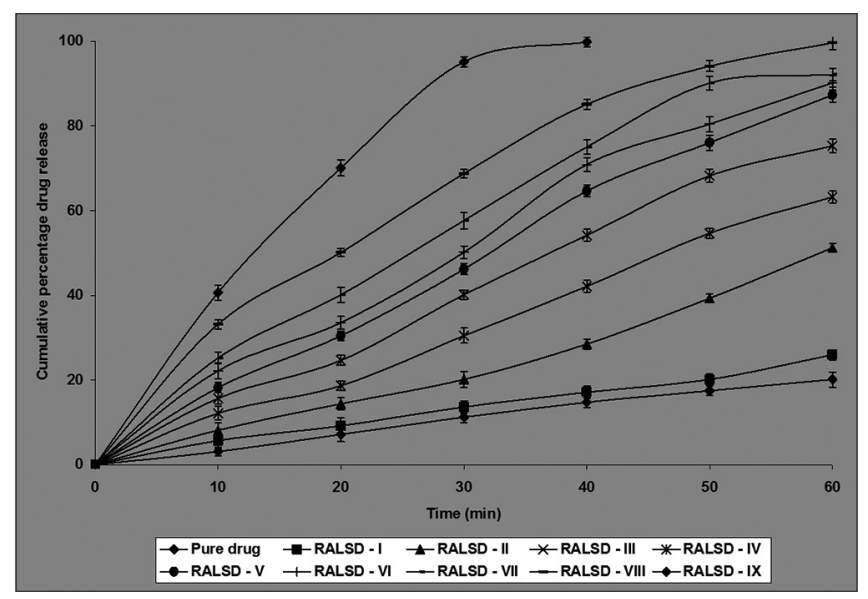

Figure 5: In vitro dissolution profiles of solid dispersion of raloxifene. Samples were withdrawn at different time intervals and raloxifene was determined by ultraviolet spectrophotometer

dissolving under sink conditions. ${ }^{[39]}$ This law describes the release from systems, where there is a change in surface area and diameter of the particles. All the formulation has shown significant increase in Hixson-Crowell cube root law [Table 3]. Hence, the release of drug from the preparations followed predominately first-order kinetics compared to

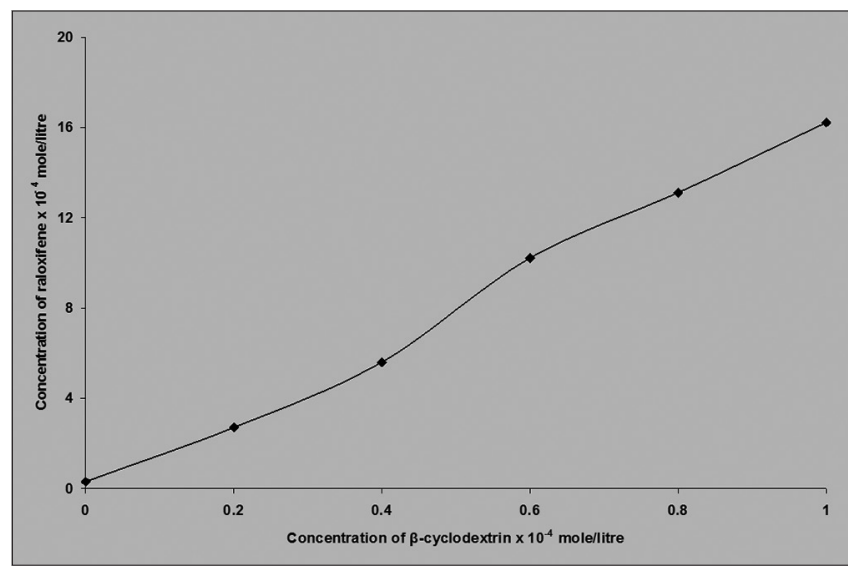

Figure 6: Phase solubility study of raloxifene and $\beta$-cyclodextrin at $25^{\circ} \mathrm{C}$

Hixson-Crowell cube root law. As the amount of carrier increased in the formulation $\mathrm{t}_{50}$ (time for dissolution of $50 \%$ of drug) values were decreased significantly, indicating there was an improvement in dissolution rate of RAL. DE is defined as the area under the dissolution curve up to the time $t$ expressed as percentage of the area of the rectangle described by $100 \%$. DE was calculated for pure RAL and all the solid dispersions (RALSD) at 10 and $30 \mathrm{~min}$ and the results were depicted in [Table 1]. Among the formulations, solid dispersions prepared in the 1:9 molar ratio shown a maximum DP of $33.17 \%$ at $\mathrm{DP}_{10}$ and $68.75 \%$ at $\mathrm{DP}_{30}$ at the end of 10 and $30 \mathrm{~min}$, respectively, while the DE of the same formulation was found to be 7.95 and $61.89 \%$ at $\mathrm{DE}_{10}$ and $\mathrm{DE}_{30}$, respectively.

\section{Release kinetics}

Table 3 enlists the regression parameters obtained after applying various release kinetics for different formulations of RAL. The release of RAL from all the formulations was 
observed to follow the first-order release kinetics as evident from higher correlation coefficient $\left(r^{2}\right)$ in comparison with zero-order kinetics. These results were in accordance with previous investigation performed by Rao et al. ${ }^{[38]}$ The correlation observed for the Higuchi matrix release kinetic in all the formulation suggesting the diffusion as a probable mechanism of drug release. ${ }^{[40]}$ In diffusion, the rate of dissolution of drug particles within the matrix must be faster than the diffusion rate of drug leaving the matrix system.

\section{CONCLUSIONS}

Phase solubility profile revealed that the solubility of raloxifene and its apparent stability constant was significantly increased in the presence of $\beta-C D$. The improvement in dissolution rate of RAL from $\beta-C D$ complexes is in agreement with the results of the solubility study. No evidence of interaction was observed between drug and carrier in FT-IR and DSC studies. The SEM and XRD studies confirmed the amorphization of drug which offered an explanation for better dissolution rate of raloxifene from solid dispersion. Solid dispersions exhibited a preferential increase in dissolution of raloxifene over pure drug. The study shows that the dissolution rate of raloxifene can be improved to a greater extent by solid dispersions technique employing an industrially feasible kneading method. The complexes prepared by the kneading method provided a dissolution rate of $95 \%$ in $30 \mathrm{~min}$, which may be of particular interest for industrial scale preparation because of low cost and simple process involving less energy, time, and equipment. It is concluded that the solid dispersion of raloxifene increased the solubility and dissolution rate of drug, suggesting a possible enhancement of its oral bioavailability.

\section{REFERENCES}

1. Amidon GL, Lennernas H, Shah VP, Crison JR. A theoretical basis for a biopharmaceutics drug classification: The correlation of in vitro drug product dissolution and in vivo bioavailability. Pharm Res 1995;12:413-20.

2. Leuner C, Dressman J. Improving drug solubility for oral delivery using solid dispersions. Eur J Pharm Biopharm 2000;50:47-60.

3. Lipinski C. Poor aqueous solubility-An industry wide problem in drug delivery. Am Pharm Rev 2002;5:82-5.

4. Hu J, Johnson KP, Williams RO. Rapid dissolving high potency danazol powders produced by spray freezing into liquid process. Int J Pharm 2004;271:145-54.

5. Aungst BJ. Novel formulation strategies for improving oral bioavailability of drugs poor membrane permeation in presystemic metabolism. J Pharm Sci 1993;82:879-987.

6. Hye JA, Kyong MK, Choi JS, Kim CK. Effects of cyclodextrin derivatives on bioavailability of ketoprofen.
Drug Dev Ind Pharm 1997;23:331-5.

7. Sekiguchi K, Obi N. Studies on absorption of eutectic mixture: I. A comparison of the behavior of eutectic mixture sulfathiazone and that of ordinary sulfathiazole in man. Chem Pharm Bull 1961;9:866-72.

8. Law SL, Lo WY, Lin FM, Chaing CH. Dissolution and absorption of nifedipine in poly ethylene glycol solid dispersion containing phosphatidyl choline. Int J Pharm 1992;84:161-6.

9. Corrigan OI. Mechanisms of dissolution of fast release solid dispersions. Drug Dev Ind Pharm 1985; 11:697-724.

10. Craig DQ. Poly ethylene glycols and drug release. Drug Dev Ind Pharm 1990;16:2501-26.

11. Ford JL. The current status of solid dispersions. Pharm Acta Helv 1986;61:69-88.

12. Madhusudhan B, Rambhav D, Gudsoorkar VR, Shete JS, Apte SS. Studies on sulphamethoxazole solid dispersions and their tablets. Indian J Pharm Sci 2002;64:233-8.

13. Delahaye N, Duclos R, Saiter JM, Varnier S. Characterization of solid dispersions phase transitions using a new optical thermal analyzer. Drug Dev Ind Pharm 1997;23:293-303.

14. Okimoto K, Miyake M, Ibuki R, Yasumura M, Ohnishi N, Nakai T. Dissolution mechanism and rate of solid dispersion particles of nilvadipine with hydroxyl propyl methyl cellulose. Int J Pharm 1997;159:85-93.

15. Yamada T, Saito N, Imai T, Otagiri M. Effect of grinding with hydroxyl propyl cellulose on the dissolution and particle size of a poorly water soluble drug. Chem Pharm Bull 1999;47:1311-3.

16. Margarit MV, Rodryguez IC, Cerezo A. Physical characteristics and dissolution kinetics of solid dispersions of ketoprofen and poly ethylene glycol 6000 . Int J Pharm 1994;108:101-7.

17. Yagi N, Terashima Y, Kenmotsu H, Sekikawa H, Takada M. Dissolution behavior of probucol from solid dispersion system of probucol-polyvinylpyrrolidone. Chem Pharm Bull 1996;44:241-4.

18. Danjo K, Nataka T, Otsuka A. Preparation and dissolution behavior of ethenzamide solid dispersion using various sugars as dispersion carriers. Chem Pharm Bull 1997;45:1840-4.

19. Narang A, Srivastava A. Evaluation of solid dispersions of clofazimine. Drug Dev Ind Pharm 1990;28:875-82.

20. Chiou WL, Riegelman S. Pharmaceutical applications of solid dispersion system. J Pharm Sci 1971;60:1281-302.

21. Chiou WL, Riegelman S. Preparation and dissolution characterization of several fast release solid dispersions of griseofulvin. J Pharm Sci 1969;58:1505-10.

22. Millic AJ, Rajic DS, Tasic LJ, Djuric S, Kasa P, Pintye HK. Etodolac and solid dispersion with $\beta$-cyclodextrin. Drug Dev Ind Pharm 1997;23:1123-9.

23. Moyano JR, Arias MJ, Gines JM, Perez JI, Rabasco AM. Dissolution behavior of oxazepam in presence of cyclodextrins, Evaluation of oxazepam-dimers binary system. Drug Dev Ind Pharm 1997;23:379-85.

24. Griensven JM, Schoemaker RC, Cohen AF, 
Luvs HG, Grafe MS, Rothig HJ. Pharmacokinetics, pharmacodynamics and bioavailability of the ACE inhibitor raloxifene. Eur J Clin Pharmacol 1995;47:513-8.

25. Shafiq S, Shakeel F, Talegaonkar S, Ahmed FJ, Khar RK, Ali M. Development and bioavailability assessment of raloxifene nanoemulsion formulation. Eur J Pharm Biopharm 2007;66:227-43.

26. Modi A, Tayade P. Enhancement of dissolution profile of solid dispersion (kneading technique). AAPS Pharm Sci Tech 2006;7:6.

27. Lachman L, Liberman HA, Kanig JL, editors. The Theory and Practice of Industrial Pharmacy. $3^{\text {rd }}$ ed. Philadelphia, PA: Varghese Lea Febiger; 1987. p. 317-8.

28. Aulton ME, Wells TI. Pharmaceutics: The Science of Dosage Form Design. London, England: Churchill Livingstone; 1988. p. 247-8.

29. Chauhan B, Shimpi S, Paradkar A. Preparation and characterization of etoricoxib solid dispersions using lipid carriers by spray drying technique. AAPS Pharm Sci Tech 2005;6:E405-12.

30. Papageorgiou GZ, Bikiaris D, Karavas E, Politis S, Docoslis A, Park Y, Stergiou A, et al. Effect of physical state and particle size distribution on dissolution enhancement of nimodipine/PEG solid dispersions prepared by melt mixing and solvent evaporation. AAPS J 2006;8:E628-31.

31. Higuchi T, Connors KA. Phase solubility techniques. Adv Anal Chem Instr 1965;4:117.

32. Khan KA. The concept of dissolution efficiency. J Pharm Pharmacol 1975;27:48-9.

33. Abdul-Fattah AM, Bhargava HN. Preparaton and in vitro evaluation of solid dispersion of halofantrine. Int
J Pharm 2002;235:17-23.

34. Szetli J. Molecular entrapment and release properties of drugs by cyclodextrins. In: Swollen VF, Ball L, editors. Controlled Drug Bioavailability: Bioavailability Control by Drug Delivery Systems Design. Vol 3. New York: Wiley Inter Science Publications; 1985. p. 365-420.

35. Sethia S, Squilante E. Solid dispersion of carbamazepine in PVP K30 by conventional solvent evaporation and supercritical methods. Int J Pharm 2004;272:1-10.

36. Martinez-Ohariz MC, Rodriguez-Espinosa C, Martin C, Goni MM, Tros-Illaduya MC, Sanchez M. Solid dispersions of diflunisal-PVP: Polymorphic and amorphous states of the Drug. Drug Dev Ind Pharm 2002;28:717-25.

37. Reddy MN, Rehana T, Ramakrishna S, Chowdary KP, Diwan VP. $\beta$-cyclodextrin complexes of celecoxib: Molecular modeling, characterization and dissolution studies. AAPS Pharm Sci Tech 2004;6:1.

38. Rao MG, Suneetha R, Reddy PS, Ravi TK. Preparation and evaluation of solid dispersions of naproxen. Indian J Pharm Sci 2005;67:26-9.

39. Hixon AW, Crowell JH. Dependence of reaction velocity upon surface and agitation. Ind Eng Chem 1931;23:923.

40. GoracinovaK,KlisarovaL, Simor A,Fredo-Kumardazi E, Petrusavska-Tozi L. Preparation, physical characterisation, mechanisms of drug/polymer interactions and stability studies of controlled release of solid dispersion granules containing weak base as active substance. Drug Dev Ind Pharm 1996;22:255-62.

Source of Support: Nil. Conflict of Interest: None declared. 